\title{
Whole exome sequencing identifies mutations in 10\% of patients with familial non-syndromic cleft lip and/ or palate in genes mutated in well-known syndromes
}

\author{
Mirta Basha, ${ }^{1}$ Bénédicte Demeer, ${ }^{1,2,3}$ Nicole Revencu, ${ }^{1,4}$ Raphael Helaers, ${ }^{1}$ \\ Stephanie Theys, ${ }^{5}$ Sami Bou Saba, ${ }^{6}$ Odile Boute, ${ }^{7}$ Bernard Devauchelle, ${ }^{8}$ \\ Geneviève Francois, ${ }^{9}$ Bénédicte Bayet, ${ }^{10}$ Miikka Vikkula $^{1}$
}

\begin{abstract}
- Additional material is published online only. To view please visit the journal online (http://dx.doi.org/10.1136/ jmedgenet-2017-105110)
\end{abstract}

For numbered affiliations see end of article.

\section{Correspondence to} Professor Miikka Vikkula, Human Molecular Genetics, de Duve Institute, University of Louvain, Brussels 1348 Belgium; miikka.vikkula@ uclouvain.be

Received 13 October 2017 Revised 2 February 2018 Accepted 12 February 2018

Published Online First 2 March 2018
Check for updates

To cite: Basha M, Demeer $B$, Revencu N, et al. J Med Genet 2018:55:449-458.

\begin{abstract}
Background Oral clefts, that is, clefts of the lip and/ or cleft palate $(\mathrm{CL} / \mathrm{P})$, are the most common craniofacial birth defects with an approximate incidence of $\sim 1 / 700$. To date, physicians stratify patients with oral clefts into either syndromic CL/P (syCL/P) or non-syndromic CL/P (nsCL/P) depending on whether the CL/P is associated with another anomaly or not. In general, patients with syCL/P follow Mendelian inheritance, while those with nsCL/P have a complex aetiology and, as such, do not adhere to Mendelian inheritance. Genome-wide association studies have identified approximately 30 risk loci for nsCL/P, which could explain a small fraction of heritability.

Methods To identify variants causing ns $C L / P$, we conducted whole exome sequencing on 84 individuals with nsCL/P, drawn from multiplex families $(n=46)$. Results We identified rare damaging variants in four genes known to be mutated in syCL/P: TP63 (one family), TBX1 (one family), LRP6 (one family) and GRHL3 (two families), and clinical reassessment confirmed the isolated nature of their CL/P.

Conclusion These data demonstrate that patients with $\mathrm{CL} / \mathrm{P}$ without cardinal signs of a syndrome may still carry a mutation in a gene linked to syCL/P. Rare coding and non-coding variants in syCL/P genes could in part explain the controversial question of 'missing heritability' for nsCL/P. Therefore, gene panels designed for diagnostic testing of syCL/P should be used for patients with nsCL/P, especially when there is at least third-degree family history. This would allow a more precise management, follow-up and genetic counselling. Moreover, stratified cohorts would allow hunting for genetic modifiers.
\end{abstract}

\section{INTRODUCTION}

Cleft lip and/or cleft palate (CL/P) are the most prevalent craniofacial birth defects. They have an approximate incidence of 1/700 live births, varying with ethnicity, gender and cleft type. ${ }^{1}$ Although $\mathrm{CL} / \mathrm{P}$ is no longer associated with mortality in higher income countries, ${ }^{2}$ it is a debilitating condition requiring expensive, invasive and often treatment until the adult age.

Syndromic CL/P (syCL/P) is typically caused by Mendelian mutation with a strongly deleterious effect on the function of a single protein, such as $I R F 6,{ }^{3}$ or by a deletion of a cluster of contiguous genes, such as del22q.11 (22qdel). ${ }^{1}$ According to OMIM, there are 148 syndromes associated with $\mathrm{CL} / \mathrm{P}$.

Non-syndromic $\mathrm{CL} / \mathrm{P}$ (nsCL/P), in contrast, is thought to have a complex aetiology, with multiple predisposing genetic variants acting in concert with intrauterine environmental effects. Epidemiological data suggest that if a child is born with a CL/P, the risk of re-occurrence in future siblings is calculated to be about $4 \%$. The risk of recurrence is similar if one parent has CL/P, $17 \%$ if one parent and one child are affected and 9\% when two children are affected. ${ }^{4}$ Non-syndromic oral clefts constitute $70 \%$ of all CL/P subjects, of which $80 \%$ are sporadic and $20 \%$ are multiplex (familial) cases. ${ }^{1}$

A common hypothesis has been that a complex disease, such as nsCL/P, is due to accumulation of predisposing common variants with a minor allele frequency $>5 \%$ in the affected subjects. ${ }^{5}$ Association studies have been performed to identify them, either focusing on candidate genes or loci disrupted by karyotype aberrations in rare patients. ${ }^{67}$ Genomewide association studies (GWASs) have also been performed, and roughly 30 loci have been identified. ${ }^{8-18}$ However, all these loci together explain only a small percentage of nsCL/P's heritability. ${ }^{19}$ Thus, the enigma of 'missing heritability' remains and animates an intense debate.

We hypothesised that part of the missing heritability could be explained by rare (private) variants that are not assayed by GWASs. Such variants can be numerous in the population, with a mediumto-high penetrance. Moreover, there is high variability in expressivity in most single-gene oral cleft syndromes suggesting influence of genetic modifiers. Thus, rare variants in genes causing syCL/P could explain part of nsCL/P. We went out to look for such variants in a cohort of 84 individuals affected with nsCL/P, drawn from multiplex families $(n=46)$.

\section{METHODS \\ Patient selection}

In close collaboration over 25 years with the multidisciplinary team at the Centre Labio-Palatin (Cliniques universitaires Saint-Luc), and a network of specialists practising in craniofacial centres worldwide, we have assembled a bio-bank of over 1300 samples of blood DNA from index subjects 
with different syndromic and non-syndromic CL/P. We have implemented systematic guidelines to collect samples uniformly. This included a detailed ascertainment of the clinical phenotype and family history by physicians, facilitated by a standardised questionnaire.

The database contains 275 families with CL/P, of which 43 families (16\%) have an IRF6 mutation, all diagnosed with a Van der Woude syndrome (VWS), either a priori (when lip pits were evident) or a posteriori (when an IRF6 mutation was identified and minor atypical lower lip signs were identified in at least one family member following scrutinised clinical examination). ${ }^{20}$ The remaining 234 families that were negative for IRF6 mutation were candidates for whole exome sequencing (WES), in order to identify new causal gene(s). We selected a total of 84 individuals drawn from 46 families classified clinically as nsCL/P cases, for which we had enough high-quality DNA for WES. When possible, we chose two to four most distant relatives per family (26/46 families, 64 individuals). For 20 families, only the index patient was sequenced. The subphenotypes of these patients ranged from fullblown complete bilateral clefts of the lip and palate (BCLP) to a much more subtle velopharyngeal insufficiency (VPI). We had a total of 7 bilateral CLP, 16 unilateral CL/P, 8 unilateral cleft lip (CL), 33 cleft palate (CP), 7 CP-posterior, 2 submucous cleft palate (SMCP), 2 SMCP with bifid uvula and 9 VPI. All selected patients had standard karyotype and many had also been tested for 22qdel, and these tests were normal. All participants and their legal guardians (when necessary) gave informed consent for the participation in the study. This study was approved by $\mathrm{La}$ Commission d'Ethique Biomédicale Hospitalo-Facultaire, reference $2015 / 02 \mathrm{NOV} / 572$, of the medical faculty at University of Louvain, Brussels, Belgium.

\section{Whole exome sequencing}

Blood was drawn in EDTA tubes, and DNA was extracted from blood samples using Wizard Genomic DNA Purification Kit (Promega). WES was carried out by using $1 \mu \mathrm{g}$ of genomic DNA per sample. Genomic DNA was fragmented into a library of small segments that can be uniformly and accurately sequenced in millions of parallel reactions. Exomes were captured using a commercial enrichment kit (Agilent SureSelectXT Human All Exon KitV5). Uncaptured DNA was washed off. Bounded DNA was clonally amplified and sequenced on Illumina HiSeq2000 to generate paired-end, $100 \mathrm{bp}$ reads. Real-time image analysis and base calling were performed by sequence control software realtime analysis and CASAVA software V.1.8 (Illumina). We achieved a mean coverage of $61 \times$ without duplicates, with $81 \%$ of target covered at least $10 \times$.

\section{Data analysis}

Generated reads were aligned to the human genome reference sequence (assembly GRCh37/hg19) by Burrows-Wheeler Aligner (see URLs). Picard Mark duplicates tool was used to flag duplicated reads (reads with a same start and end coordinates), which were subsequently removed from downstream analysis. SAM tools consolidated all BAM files (aligned reads). Local realignments around indels and base quality score recalibration were done with the Genome Analysis Toolkit (GATK) V.2.8. Variants were called using the GATK Unified Genotyper. Each called variant was annotated using Highlander software, an in-house bioinformatic framework (see URLs) (Helaers et al, under revision). On average, each patient had \pm 20 000-25000 variants.
In silico analysis of called variants

We analysed variants in each family and in each sporadic subject independently. We retained variants for further analysis if they met the following criteria: $(1) \leq 1 \%$ in Exome Aggregation Consortium (ExAC), (2) $\leq 1 \%$ in 1000 genomes project, (3) $\leq 0.5 \%$ in Go-NL (genome of the Netherlands), (4) $\leq 1 \%$ in in-house controls (subjects affected with different condition than $\mathrm{CL} / \mathrm{P}$ ) and (5) estimated by visual inspection on Integrative Genomics Viewer/GATK scores as true variants.

As 'likely pathogenic' variants, we considered those with a high impact (canonical splice-site variants and those generating a premature termination codon, PTC (out-of-frame indels and nonsense variants)), or a moderate impact (missense), as predicted by SnpEff software. We prioritised variants in genes intolerant to loss-of-function ( $\mathrm{LoF}$ ) and/or variation, as estimated from the PLi values and z-scores derived from ExAC. We considered missense variants to have a deleterious effect when at least three out of six software (Sift, Polyphen, LRT, Mutation taster, Mutation assessor, FATHMM) predicted them as damaging. To maximise the conclusion that any novel, damaging variant would be causal, we focused on a list of about 500 (functional) candidate genes that we gathered from Jugessur and coworkers (ie, 357 biologically plausible, autosomal candidate genes for oral clefts), ${ }^{21}$ augmented by novel genes presented at recent craniofacial conferences and or publications. We used the Genome Aggregation Database (gnomAD) to evaluate the frequency of the identified variants in a larger control population.

For all variants that satisfied our criteria, we performed co-segregation analysis on all the affected and non-affected family members when available. Approximately 15-20 variants/ family and $\sim 20-30$ variants/sporadic subject were PCR-amplified followed by sequencing on an ABI 3130XL genetic analyser (Applied BioSystems).

To evaluate genotype-phenotype correlations in the identified genes, we gathered all intragenic published mutations from HGMD, denovo-db and current literature. We considered only missense, nonsense, canonical splice sites and exonic small indels. These variants were dichotomised into either missense/ in-frame indels or LoF (out-of-frame indels, nonsense and canonical splice-site variants).

\section{Validation of mRNA stability}

RNA was extracted from blood samples (lymphocytes) with TriPure (Roche) and retrotranscribed using RevertAid H Minus First Strand cDNA Synthesis Kit (Fermentas) with random hexamers. PCR-amplification was done on cDNA using a primer pair, forward in exon 2_3 (CCACCTGGACGTATTCCACT) and reverse in exon 5 (ACTTGCCCATCTCTGGTTTC). Amplicon's size (433 bp) was evaluated with an agarose gel, using GeneRuler 100 bp (Thermo Scientific) DNA ladder.

\section{RESULTS}

\section{Family 1: TP63 mutation}

In family CLP-1055, we identified a $2 \mathrm{bp}$ insertion (NM_003722.4: c.819_820dupCC) in exon 6 of TP63 in the father and the proband (figure 1-F1). This mutation leads to a frame-shift with a PTC (NP_003713.3: p.Gln274fs*4:). The insertion is not known in the gnomAD containing 246,134 TP63 alleles. The gene is intolerant for LoF mutations as evidenced by the PLi value of 0.98 (divergence between observed and expected counts for LoF changes) provided by ExAC. In all the 12 known TP63 coding transcripts, the frame-shift is predicted to induce PTC in an evolutionary conserved DNA binding 


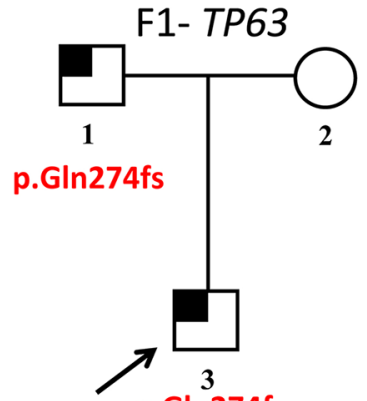

p.GIn274fs
F2-TBX1

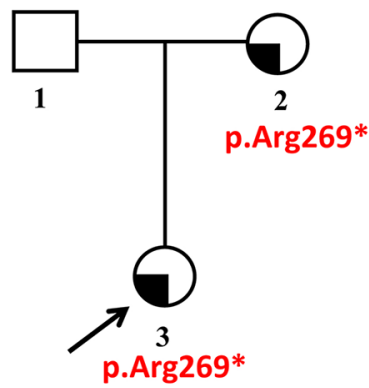

F4a-GRHL3

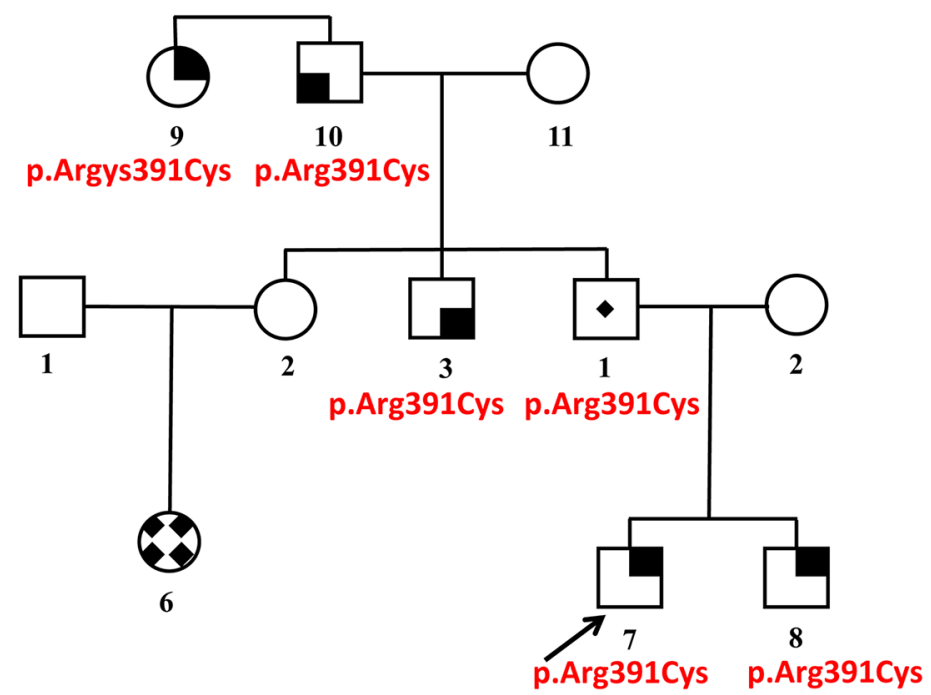

F3-LRP6

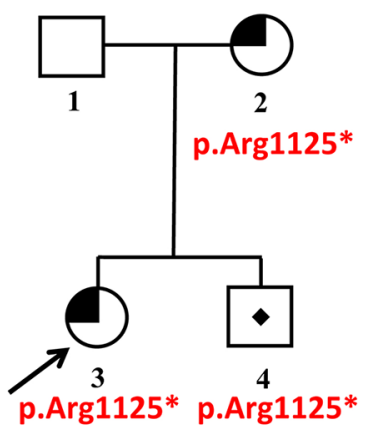

Figure 1 Five pedigrees with four mutations in cleft lip and/or palate (CL/P) syndrome causing genes. Family number and mutated gene marked above the pedigree (F-\#-gene). Mutation is given underneath each carrier/affected. Gender symbols shaded with solid black areas indicate the subphenotype of CL/P. Upper right, CL/P; upper left, cleft palate (CP) or Pierre-Robin sequence; lower left, submucous cleft palate \pm bifid uvula; lower right, velopharyngeal insufficiency and/or hypernasal speech. Gender symbols with a central dot indicate carriers. A female symbol with a solid diamond pattern indicates a phenocopy CP. An arrow marks proband in each family.

domain (figure 2). Further, mRNA studies demonstrated that the mutant allele underwent nonsense-mediated-mRNA decay (NMD) as only the wild-type allele observed in mRNA obtained from the patient's lymphocytes and lymphoblasts.

The proband had a unilateral, right-sided CLP. He had no limb anomaly, no ectodermal dysplasia and no cardiac malformation. Follow-up until the age of 3.5 years showed growth and development within normal limits. His father had a unilateral, left-sided CLP. Both were re-examined for minor symptoms of TP63 disorders, yet they sustained their initial classification as nsCL/P.

\section{Family 2: TBX1 mutation}

In family CLP-678, we identified a nucleotide change (NM_080647.1: c.805C>T:) in exon 6 of TBX1 in the mother and the proband (figure $1-\mathrm{F} 2$ ). This nonsense mutation (NP_542378.1: p.Arg269*: NP_542378.1) is located in the T-Box domain (figure 3 ). The substitution is unknown in gnomAD containing 277208 TBX1 alleles. As TBX1 mRNA is not expressed in lymphocytes or lymphoblasts, mRNA stability could not be studied.

The index subject was born at 35.5 weeks of gestation. She had neonatal regurgitations and bradycardia. A diagnosis of VPI with severe hypotonia of the velopharyngeal musculature was made, but the $22 \mathrm{q} 11$ deletion test was normal. Follow-ups showed normal development, no particular facial gestalt, yet with a persistent hypernasal speech (a consequence of VPI), despite receiving speech therapy. Apart from a neonatal patent ductus arteriosus, the index case had no cardiac structural defect.

The proband's mother also had isolated VPI. She underwent surgery at the age of 23 years, with partial improvement. Cardiac ultrasound did not reveal any cardiac defect.

\section{Family 3: LRP6 mutation}

In family CLP-451, we identified a nucleotide change (NM_002336.2: c.3373C>T:) in exon 15 of the LDL receptor related protein 6 (LRP6) in three individuals (figure 1-F3). The substitution is not known in gnomAD containing 277132 LRP6 alleles. This nonsense variant (NP_002327.2: p.Arg1125*:) is located in a conserved YWTD repeat in the fourth $\beta$-propeller domain (figure 4).

The proband had a BCLP with missing upper lateral incisors, and her mother had a bilateral CL. Proband's brother is an unaffected carrier of the substitution. We could not exclude oligodontia ( $>6$ missing teeth) in any of the three mutation carriers since the family was not available for reassessment. 
Total

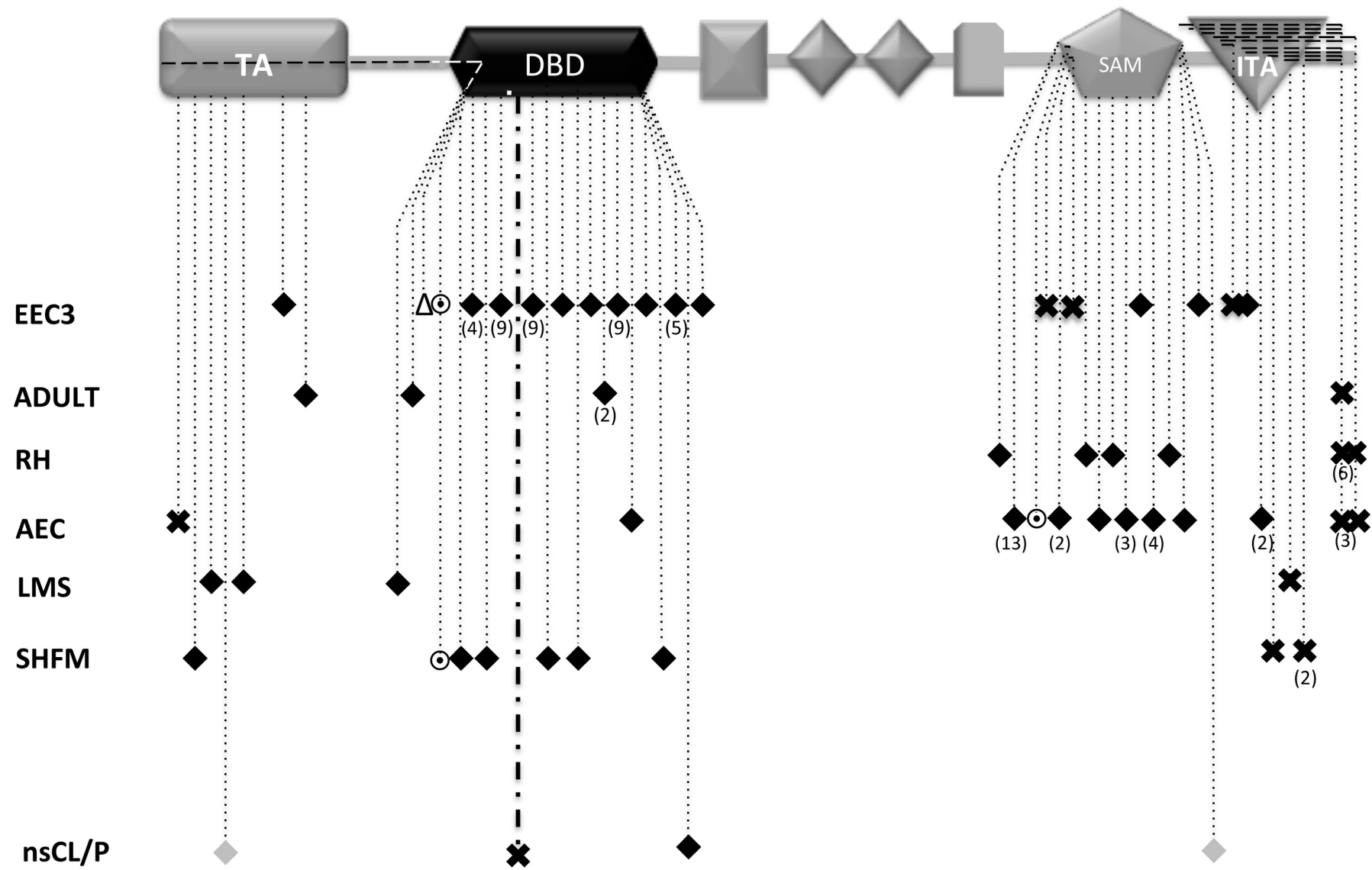

CLP-1055 (p.GIn274fs*4)

Figure 2 TP63 protein structure; domains/motifs represented by different geometrical shapes (all scaled). ADULT, acro-dermato-ungual-lacrimal-tooth syndrome; AEC, ankyloblepharon-ectodermal defects-cleft lip/palate; DBD, DNA-binding domain; EEC3, ectrodactyly, ectodermal dysplasia and cleft lip/ palate syndrome 3; ITA, inhibitor of transactivation domain; LMS, limb-mammary syndrome; RH, Rapp-Hodgkin syndrome; SAM, sterile alpha motif; SHFM, split/hand-foot malformation; TA, transactivation domain. Symbols: $\boldsymbol{*}$, loss-of-function variants (exonic premature termination codon, out-of-frame indel and canonical splice-site variant); dashed line across protein, out-of-frame indel from start to end; $\bigcirc$, in-frame indel; $\bullet$, missense variants (neomutation, or present in a minimum of two affected, or functionally validated); $\bullet$, other rare missense variant; dashed line across protein ending with $\Delta$, a large $5^{\prime}$ deletion of several exons; number in parentheses, number of occurrences in index patients, mutations in close proximity grouped (see online supplementary table S1).

\section{Families 4 and 5: GRHL3 mutation}

We identified an identical nucleotide change (NM 198174.2: c. $1171 \mathrm{C}>\mathrm{T}$ :) in exon 9 of Grainyhead-like transcription factor 3 (GRHL3) in two families CLP-398 (figure 1-F4a and CLP-986 (figure $1-\mathrm{F} 4 \mathrm{~b}$ ). The substitution is listed once in gnomAD containing 244128 GRHL3 alleles. This variant leads to an arginine-to-cysteine substitution (NP_002327.2: p.Arg391Cys) in an evolutionarily conserved DNA-binding domain (figure 5). This change has been reported as a de novo variant in two patients, one with a CLP and lip pits, ${ }^{22}$ the other with spina bifida. ${ }^{23}$ In vitro and in vivo studies demonstrated a dominant negative effect. ${ }^{22} 24$

The proband in family CLP-398 had a Pierre-Robin sequence (PRS) (figure 1-F4a). His brother had a milder PRS. On the paternal side, an uncle had a high-arched palate with a SMCP and missing upper lateral incisors. A paternal great-aunt had a surgically repaired CP. The grandfather has hypernasal speech, according to family history. The father of the proband is an unaffected carrier.

The proband in family CLP-986 had a posterior CP (affecting the soft palate). His father had a SMCP with a bifid uvula (figure 1-F4b). Abnormalities of the lower lip, such as lip pits associated with the VWS, were excluded following detailed clinical examination in both families.

\section{DISCUSSION}

We identified altogether 5 out of 46 index patients screened to have a clear mutation in a gene mutated in specific syndromes associated with oral clefts. The pick-up frequency among them is thus about $10 \%(5 / 46)$. These were all subjects with family history of nsCL/P. In total, there were 15 mutation carriers. Penetrance was high 13/15 (87\%). Apart from family CLP-451, all patients were clinically re-examined for minor signs of $\mathrm{CL} / \mathrm{P}$ syndromes. The assessment confirmed the isolated occurrence of 


\section{TBX1}

Missense \& In-frame indels

Nonsense

Total
11

7

18

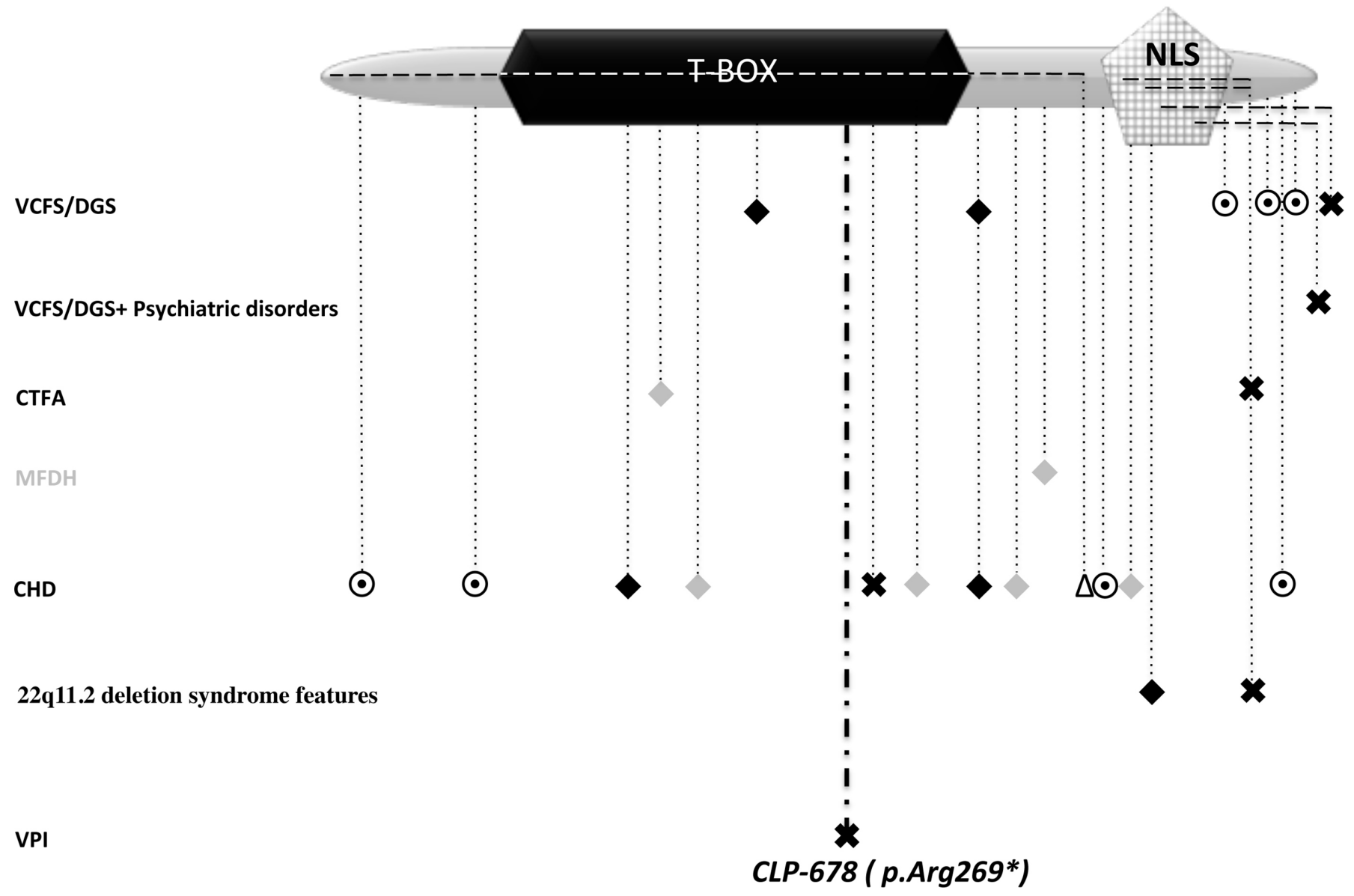

Figure 3 TBX1 protein structure; domains/motifs represented by different geometrical shapes (all scaled). CHD, congenital heart defect; CTFA, conotruncal face anomaly syndrome; MFDH, midline facial defects with hypertelorism; NLS, nuclear localisation signal; T-BOX, DNA-binding domain; VCFS/ DGS, velocardiofacial syndrome/DiGeroge syndrome; VCFS/DGS + psychiatric disorders such as depression and Asperger syndrome; VPI, velopharyngeal insufficiency. Symbols: $\boldsymbol{*}$, loss-of-function variants (exonic premature termination codon, out-of-frame indel and canonical splice-site variant); dashed line across protein, out-of-frame indel from start to end; $\bigcirc$, in-frame indel; $\diamond$, missense variant (neomutation, or present in a minimum of two affected, or functionally validated); $\diamond$, other rare missense variant; dashed line across protein ending with $\Delta$, a large $5^{\prime}$ deletion of several exons (see online supplementary table S2).

$\mathrm{CL} / \mathrm{P}$. This underscores the extreme variability in expressivity in phenotypes caused by mutations in these genes, which can range from a full-spectrum syndrome to a most subtle CL/P subphenotype such as VPI.

In total, four mutations in four different genes were identified in five families (one mutation was shared by two unrelated families). The four mutations co-segregated with the oral cleft in an autosomal dominant manner in all families. They belong to the less frequent group, when known mutations are dichotomised into LoF (PTC or variant in a canonical splice site) and missense mutations. In TP63, TBX1 and LRP6, in which we identified a LoF mutation, LoF variants account for only 21/103 (figure 2), 7/18 (figure 3) and 9/28 (figure 4), respectively. In contrast, in GRHL3 (figure 5), in which we identified a missense mutation, validated missense variants ${ }^{23} 24$ account for only 7/20.

In two of the four genes, localisation of our mutations did not follow the typical grouping of mutations by type. In both TP63 and TBX1, the few known LoF mutations cluster to the $3^{\prime}$ end of the gene (figures 2-3 and online supplementary tables S1 and S2) and have been identified in patients with a full-blown syndrome, such as EEC3 (ectrodactyly, ectodermal dysplasia MIM \#604292, and cleft lip/palate syndrome 3), ADULT (acro-dermato-ungual-lacrimal-tooth syndrome MIM \#103285), RH (Rapp-Hodgkin syndrome MIM \#19400), AEC (ankyloblepharon-ectodermal defects-cleft lip/palate MIM\#19400), LMS (limb-mammary syndrome MIM \#603543), SHFM (split/ hand-foot malformation 4 MIM \# 605289) or (VCFS/DGS), respectively (figures 2-3). Our LoF mutations localised to the DNA-binding domain, in the middle of the two proteins. Thus, there seems to be a genotype-phenotype correlation regarding mutation type and/or localisation for these genes.

TP63 encodes a transcription factor, which is a master regulator of epithelial lineage commitment during and after development. Heterozygous germ-line mutations in TP63 underlie at least six disorders with overlapping phenotypes, which share ectrodactyly, ectodermal dysplasia, cleft lip/palate (EEC), lacrimal duct obstruction, hypopigmentation and hyperplastic breasts and/ or nipples to varying degrees. Mutations are dispersed in all 
LRP6

Missense \& In-frame indels 19

Nonsense 9

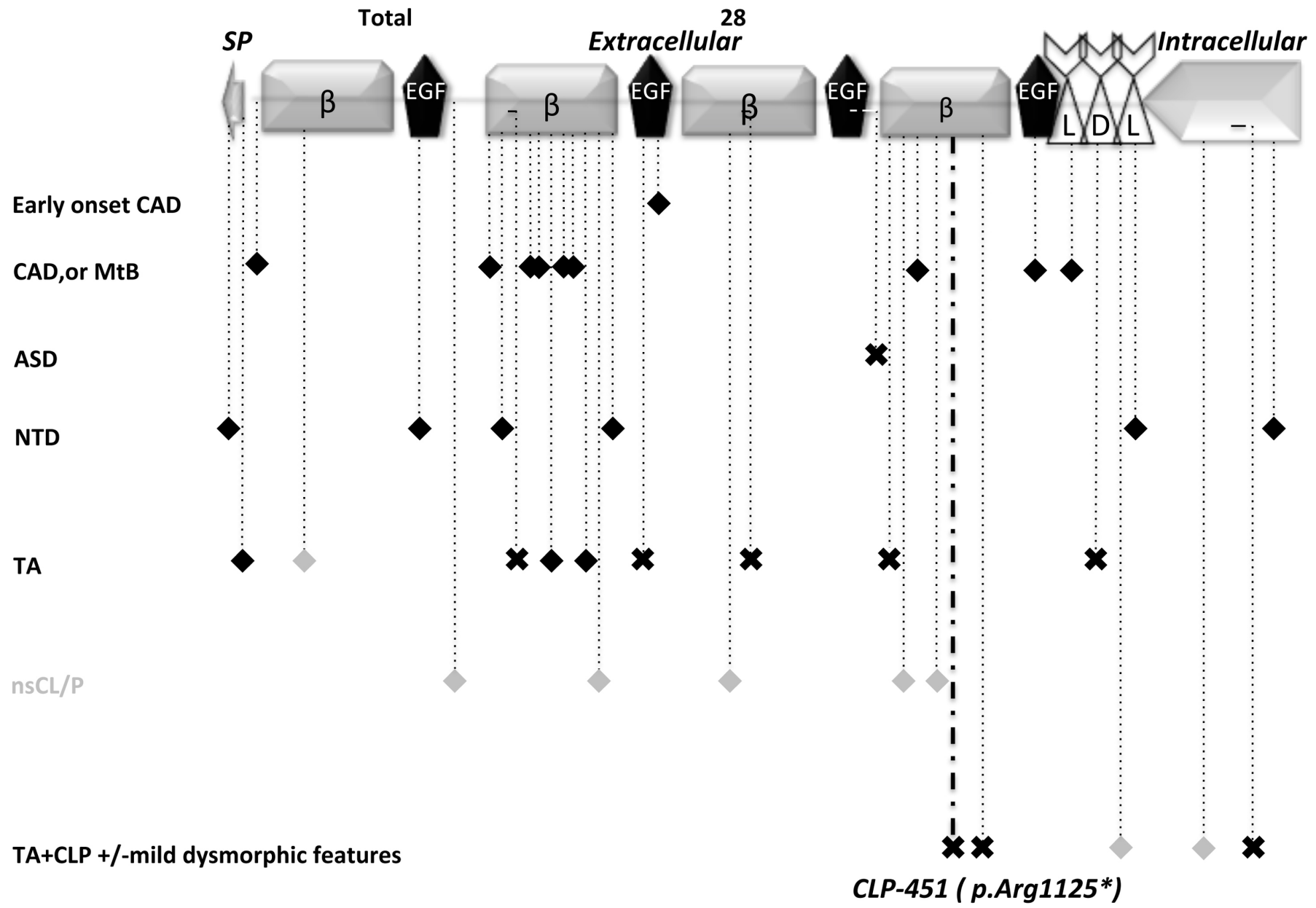

Figure $4 \quad L R P 6$ protein structure; domains/motifs represented by different geometrical shapes (all scaled). ASD, autism spectrum disorder; CAD, coronary artery disease; $C L P$, cleft lip and palate; MtB, metabolic syndrome; $n s C L / P$, non-syndromic cleft lip and/or palate; NTD, neural tube defect; TA, tooth agenesis; TA+CL/P, combined tooth agenesis with CLP and mild dysmorphic features. Extracellular part: $\beta$, $\beta$ propeller repeats; EGF, epidermal growth factor-like domain; LDL, LDL type A-like receptor; SP, signal peptide. Symbols: $\boldsymbol{x}$, loss-of-function variants (exonic premature termination codon, out-of-frame indel and canonical splice-site variant); dashed line across protein, out-of-frame indel from start to end; $\bullet$, missense variant (neomutation, or present in a minimum of two affected, or functionally validated); $\diamond$, other rare missense variant (see online supplementary table S3).

functional domains of TP63, with a well-established genotypephenotype correlation (figure 2). Penetrance is incomplete and variable expressivity is observed. EEC point mutations cluster in the DNA binding domain (DBD) and have a disruptive effect on DNA binding characteristics of all expressed isoforms. The effects of these mutations on the counterpart wild-type allele are thought to be dominant negative. ${ }^{25}$ To our best knowledge, this is a first reported indel mutation within the DBD domain. Yet, the position is not that important, as the transcribed allele undergoes mRNA decay. A larger deletion extending from exon 1 to exon 4 (encompassing most of DBD) was reported in a patient with EEC3. ${ }^{26}$ It is not known if a stable TP63 lacking most of the DBD domain is produced starting from one of downstream in-frame ATGs and what kind of activity such a short form would have.

Whether TP63's haploinsufficiency could also be the pathomechanism for some types of TP63 disorders has been a subject of debate and was originally refuted based on inferences from mouse model phenotypes when compared with humans. Tp $63^{-/-}$ mice recapitulate the phenotypic spectrum observed in humans with a $T P 63^{+/-}$mutation, ${ }^{27}$ while tp $63^{-/+}$mice nor patients with a 3q27del do not exhibit ectodermal defects. ${ }^{27}$ However, recent publications report patients with ectodermal dysplasia and higharched palate ${ }^{28}$ among other symptoms with a $3 \mathrm{q} 27.3 \mathrm{del}$ and a variable expressivity in a CP family with $3 \mathrm{q} 28 \mathrm{del}^{29}$ This suggests that TP63 haploinsufficiency can be a driving mechanism behind clefting. Therefore, the identified TP63 LoF allele, which manifests as isolated nsCLP, suggests it to be a haploinsufficient allele.

TBX1 maps to $22 \mathrm{q} 11.2$, a region frequently deleted in humans $(\sim 1 / 4000$ live births). It is associated with DiGeorge syndrome (DGS)/velocardiofacial syndrome (VCFS) (MIM 192430/188400). It regulates a number of genes via epigenetic modifications. ${ }^{30} 31$ TBX1 mutations manifest with pharyngeal arch-related developmental defects, affecting the heart, thymus and parathyroid gland. TBX1 mutations cause a recognisable spectrum of craniofacial anomalies such as CP, or VPI with typical facies and a predilection to develop neuropsychiatric disorders.

Phenotypic discordance was observed in cases with an identical deletion and also among monozygotic twins. ${ }^{32}$ Deleterious variants located within the Brachyury $\mathrm{T}$ domain (a well-conserved 


\section{GRHL3}

$\begin{array}{ll}\text { Missense } & 7 \\ \text { Nonsense } & 13 \\ & 20\end{array}$

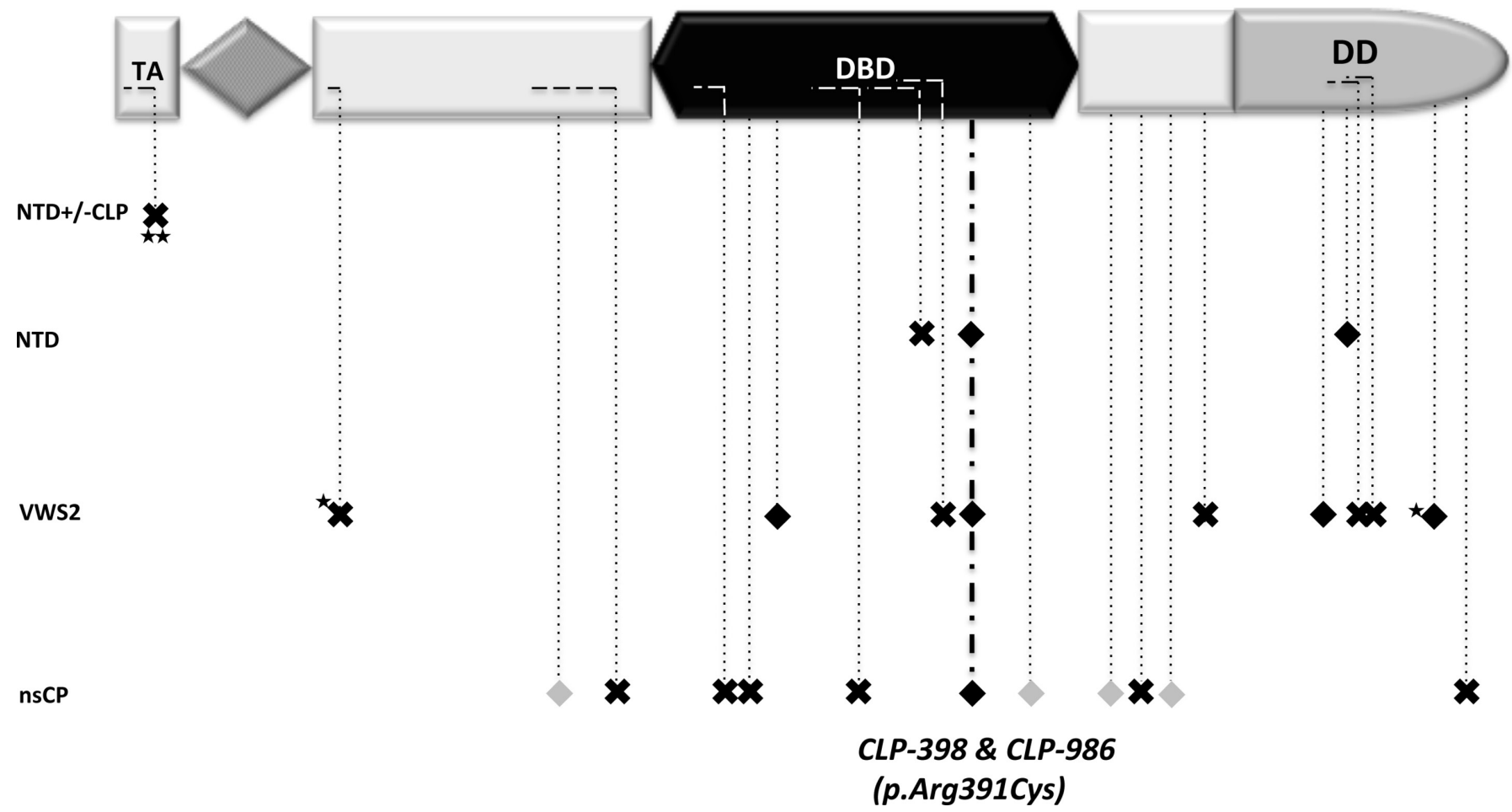

Figure 5 GRHL3 protein structure; domains/motifs represented by different geometrical shapes (all scaled). CLP, cleft lip and palate; DBD, DNA-binding domain; DD, dimerisation domain; NTD, neural tube defect; nsCP, non-syndromic cleft palate; TA, transactivation domain; VWS2, Van der Woude syndrome 2. Symbols: $\boldsymbol{*}$, loss-of-function variants (exonic premature termination codon, out-of-frame indel and canonical splice-site variant); dashed line across protein, out-of-frame indel from start to end; $\bullet$, missense variant (neomutation, or present in a minimum of two affected, or functionally validated); $\diamond$, other rare missense variant; ${ }^{\star}$, compound heterozygous mutations, identified in a single family; ${ }^{\star \star}$, homozygous mutation (see online supplementary table S4).

DBD, shared with T-Box family members) are associated with DGS/VCFS (figure 3 and online supplementary table S2) and some variants are associated with isolated congenital heart defects (CHDs) (figure 3 and online supplementary table S2). In vitro investigations by luciferase assay demonstrated that the only identified PTC in the DNA-binding domain of TBX1 p.Glu277*, which co-segregated in a family with CHD, is a LoF variant. ${ }^{33}$ This variant is distal to our p.Arg269* variant, which manifests as isolated VPI without any cardiac defect. There are another four reported frame-shift mutations towards the $3^{\prime}$ end of TBX1, all disrupting the nuclear localisation signal (figure 3). These mutants, if stable, could inhibit TBX1 dimer formation and thus have dominant-negative effects on the function of the remaining wild-type allele. The extreme variability in phenotypic expressivity and penetrance suggests that depending on the mutation's type and localisation, they have different effects on TBX1 function, and that other, genetic co-factors play an important role.

Mutations in LRP6, a well-studied co-receptor in WNT/ $\beta$-catenin-dependent signalling pathway, have a pleiotropic role in disease (figure 4 and online supplementary table S3). ${ }^{34}$ Lrp6 mimics WNT activity in enhancing neural crest formation, ${ }^{35}$ which gives rise to diverse cell lineages including cranioneural crest cells. LRP6 mutations are associated with congenital neural tube defects, ${ }^{3637}$ and severe tooth agenesis, ${ }^{38}$ sometimes with CLP. ${ }^{39}$ The nonsense mutation we identified is located in the extracellular domain of LRP6 causing haploinsufficiency. It is located adjacent to previously identified LoF heterozygous mutations, which cause autosomal tooth agenesis with reduced penetrance. In vitro studies showed that the p.Ala19Val mutant LRP6 was retained in the endoplasmic reticulum, ${ }^{38}$ which prevented it from being visible for incoming ligands at the cell surface. This suggests that the not fully penetrant tooth agenesis phenotype is due to loss of membrane-bound LRP6 signalling. A combined phenotype (tooth agenesis and CLP) was observed in another patient with a truncating variant in the last exon of LRP6 (intracellular; figure 4). Although it is expected to escape NMD, this variant is at least partially inactive since it loses three of its five signature PPPSP motifs, ${ }^{40}$ crucial for phosphorylation of LRP6 and WNT activation. Whether mutation type and position alone, or interaction with co-factors, explain the phenotypic variability associated with LRP6 mutations remains to be seen.

GRHL3 was identified by linkage to the region 1p33-36 in a large Finnish family affected with VWS2 (MIM 606714). It was screened in a series of $\mathrm{nsCP}$ and VWS2 suspects. Mutations' effects ranged from dominant negative to strong and moderate hypomorphs (figure 5 and online supplementary table S4). ${ }^{22241}$ The latter mechanism loses some of its activity compared with the wild type, and as such predisposes rather than causes nsCP/VWS2. Our identified variant p.Arg391Cys has a dominant negative effect. It is associated with intriguing 
variability in phenotypic expressivity. As a de novo mutation, it manifested with CLP and lip pits in one Filipino subject, while with isolated spina bifida in a second subject. We identified it as a germline mutation in two families of Belgian descent, both of which display a remarkable intrafamilial and interfamilial variability varying from PRS and CP to hypernasal speech (figure $1-\mathrm{F} 4 \mathrm{a}-\mathrm{F} 4 \mathrm{~b}$ ). Given that this mutation is a $\mathrm{C}>\mathrm{T}$ transition, occurring in a $\mathrm{CpG}$ dinucleotide known to easily undergo deamination, this mutation likely represents a mutational 'hot-spot'. The occurrence in different ethnicities underscores this.

Lip pits, a hallmark of VWS, with an approximate penetrance of $80 \%$, is observed in about $30 \%$ of patients with a GRHL3 mutation. ${ }^{2241}$ However, lip pits were not present in either one of our families contrary to the aforementioned patient with VWS2. Although mild micrognathia was described, PRS observed in the proband and his sibling in family CLP-398 is novel and demonstrates once more the important clinical variability associated with variants in oral cleft 'syndrome-causing' genes, and the necessary quest to investigate modifiers.

Our results, as well as previously published data including IRF6, ${ }^{20}{ }^{42} \mathrm{MSX}^{43}{ }^{43} \mathrm{TBX}_{2} 2^{44}$ and $\mathrm{GRHL} 3,{ }^{41}$ substantiate evidence for Mendelian transmission (with incomplete penetrance) of aetiological variants in 'syndrome-causing genes' in subclinical or non-syndromic cleft families. Therefore, custom-designed panels including CL/P-syndrome-causing genes should be used in diagnostic screens when a particular syndrome is suspected and also for families with nsCL/P. The benefits are dual; this will improve genetic counselling (by providing more informative chances of inheritance of $25 \%-50 \%$ versus an empiric of $4 \%-17 \%$ ) and phenotyping of the patients (in search of minor/overlooked symptoms relevant to the syndrome) and also expand our understanding of molecular mechanisms underlying $\mathrm{CL} / \mathrm{P}$.

Such diagnostic screens will deliver many rare variants that will stratify CL/P cohorts more uniformly. Using genomic technologies such as WES or WGS (whole genome sequencing) on stratified cohorts will subsequently facilitate the teasing out of genetic modifiers such as coding variants in other genes, distantly acting enhancers, promoters and other conserved non-coding regions. Another unexplored explanation for sporadic CL/P are somatic mutations in developmentally relevant tissues in one of the known syndrome-linked genes. Proof of this concept has already elegantly been shown for various sporadically occurring vascular anomalies. ${ }^{45}{ }^{46}$ Unfortunately, targeted exomes and/or genomes of relevant tissues to $\mathrm{CL} / \mathrm{P}$ are not that feasible to perform, until we determine the exact relevant tissues.

\section{Concluding remarks}

When syndromes manifest at the mild end of their spectra, they are often overlooked by clinicians. Our study clearly demonstrates the need to broaden criteria for diagnostic genetic screens to include patients with nsCL/P with a family history, as in $10 \%$ of them a causative Mendelian mutation could be identified. It could be that in an important percentage of the remaining cases, the same genes are involved due to an indel or copy number alteration (CNVs) not easily detectable by WES. WGS will therefore likely be the best choice for diagnostic screens of families with a history of nsCL/P.

\section{Author affiliations}

${ }^{1}$ Human Molecular Genetics, de Duve Institute, University of Louvain, Brussels, Belgium
${ }^{2}$ Center for Human Genetics, CLAD nord de France, CHU Amiens, Amiens, France ${ }^{3}$ EA 4666, Université Picardie Jules Verne, Amiens, France

${ }^{4}$ Center for Human Genetics, Cliniques universitaires Saint-Luc, University of Louvain, Brussels, Belgium

${ }^{5}$ Pediatric Dentistry and Oral Care for Special Needs, Cliniques universitaires SaintLuc, University of Louvain, Brussels, Belgium

${ }^{6}$ Department of Orthodontics and Dentofacial Orthopedics, Cliniques universitaires Saint-Luc, University of Louvain, Brussels, Belgium

${ }^{7}$ Service de génétique clinique Guy Fontaine, CHRU de Lille - Hôpital Jeanne de Flandre, Lille, France

${ }^{8}$ Service of Maxillofacial Surgery and Stomatology, CHU Amiens-Picardie, Amiens, France

${ }^{9}$ Department of Pediatrics, Cliniques universitaires Saint-Luc, University of Louvain, Brussels, Belgium

${ }^{10}$ Division of Plastic Surgery, Centre Labio-Palatin, Cliniques universitaires Saint-Luc, University of Louvain, Brussels, Belgium

Contributors $\mathrm{MB}$ and $\mathrm{MV}$ prepared the manuscript. MB performed patient selection for WES, WES data analysis and validation/co-segregation of identified variants. $B D, N R$ and $B B$ were in charge of enrolment of subjects and collecting samples. RH helped in bioinformatic analyses of WES data. BD, NR, ST, SBS, OB, BD $\mathrm{GF}$ and $\mathrm{BB}$ collected the clinical data. All authors contributed to re-drafting of the manuscript. MV conceived and coordinated the project and is responsible for the overall content. All authors have seen and approved the final manuscript.

Funding These studies were partially supported by funding from the Belgian Science Policy Office Interuniversity Attraction Poles (BELSPO-IAP) programme through the project IAP P7/43-BeMGI; Bridgelris RBC/2013-PFS-EH-11; the Fonds de la Recherche Scientifique-FNRS; CdR: J.0080.16 (all to MV). We also acknowledge the support of la Communauté française de Wallonie-Bruxelles, la Lotterie Nationale, Belgium and la région Haut de France, France. The authors thank the Genomics Platform of Université catholique de Louvain for next-generation sequencing analyses and the Foundation against Cancer, Belgium.

Competing interests None declared.

Patient consent Not required.

Ethics approval This study obtained 'La Commission d'Ethique Biomédicale Hospitalo-Facultaire' approval (2015/02NOV/572) by the medical faculty at University of Louvain, Brussels, Belgium.

Provenance and peer review Not commissioned; externally peer reviewed.

Data sharing statement All data relating to the study are available within the manuscript and accompanying online supplementary files.

(c) Article author(s) (or their employer(s) unless otherwise stated in the text of the article) 2018. All rights reserved. No commercial use is permitted unless otherwise expressly granted.

\section{REFERENCES}

1 Mossey PA, Modell B. Epidemiology of oral clefts 2012: an international perspective. Front Oral Biol 2012;16:1-18.

2 Mulliken JB. The changing faces of children with cleft lip and palate. N Eng/ J Med 2004;351:745-7

3 Kondo S, Schutte BC, Richardson RJ, Bjork BC, Knight AS, Watanabe Y, Howard E, de Lima RL, Daack-Hirsch S, Sander A, McDonald-McGinn DM, Zackai EH, Lammer EJ, Aylsworth AS, Ardinger HH, Lidral AC, Pober BR, Moreno L, Arcos-Burgos M, Valencia C, Houdayer C, Bahuau M, Moretti-Ferreira D, Richieri-Costa A, Dixon MJ, Murray JC. Mutations in IRF6 cause Van der Woude and popliteal pterygium syndromes. Nat Genet 2002;32:285-9.

4 Curtis EJ. Congenital cleft lip and palate. Am J Dis Child 1961;102:853-7.

5 Reich DE, Lander ES. On the allelic spectrum of human disease. Trends Genet 2001;17:502-10.

6 Ghassibé M, Bayet B, Revencu N, Verellen-Dumoulin C, Gillerot Y, Vanwijck R, Vikkula $M$. Interferon regulatory factor-6: a gene predisposing to isolated cleft lip with or without cleft palate in the Belgian population. Eur I Hum Genet 2005;13:1239-42.

7 Ghassibe-Sabbagh M, Desmyter L, Langenberg T, Claes F, Boute O, Bayet B, Pellerin P, Hermans K, Backx L, Mansilla MA, Imoehl S, Nowak S, Ludwig KU, Baluardo C, Ferrian M, Mossey PA, Noethen M, Dewerchin M, François G, Revencu N, Vanwijck R, Hecht J, Mangold E, Murray J, Rubini M, Vermeesch JR, Poirel HA, Carmeliet P, Vikkula M. FAF1, a gene that is disrupted in cleft palate and has conserved function in zebrafish. Am J Hum Genet 2011:88:150-61.

8 Birnbaum S, Ludwig KU, Reutter H, Herms S, Steffens M, Rubini M, Baluardo C, Ferrian M, Almeida de Assis N, Alblas MA, Barth S, Freudenberg J, Lauster C, Schmidt G, Scheer M, Braumann B, Bergé SJ, Reich RH, Schiefke F, Hemprich A, Pötzsch S, Steegers-Theunissen RP, Pötzsch B, Moebus S, Horsthemke B, Kramer FJ, Wienker TF, Mossey PA, Propping P, Cichon S, Hoffmann P, Knapp M, Nöthen MM, Mangold 
E. Key susceptibility locus for nonsyndromic cleft lip with or without cleft palate on chromosome 8q24. Nat Genet 2009;41:473-7.

9 Grant SF, Wang K, Zhang H, Glaberson W, Annaiah K, Kim CE, Bradfield JP, Glessner JT, Thomas KA, Garris M, Frackelton EC, Otieno FG, Chiavacci RM, Nah HD, Kirschner RE, Hakonarson H. A genome-wide association study identifies a locus for nonsyndromic cleft lip with or without cleft palate on 8q24. J Pediatr 2009;155:909-13.

10 Beaty TH, Murray JC, Marazita ML, Munger RG, Ruczinski I, Hetmanski JB, Liang KY, Wu T, Murray T, Fallin MD, Redett RA, Raymond G, Schwender H, Jin SC, Cooper ME, Dunnwald M, Mansilla MA, Leslie E, Bullard S, Lidral AC, Moreno LM, Menezes R, Vieira AR, Petrin A, Wilcox AJ, Lie RT, Jabs EW, Wu-Chou YH, Chen PK, Wang H, Ye $X$, Huang S, Yeow V, Chong SS, Jee SH, Shi B, Christensen K, Melbye M, Doheny KF, Pugh EW, Ling H, Castilla EE, Czeizel AE, Ma L, Field LL, Brody L, Pangilinan F, Mills JL, Molloy AM, Kirke PN, Scott JM, Scott JM, Arcos-Burgos M, Scott AF. A genome-wide association study of cleft lip with and without cleft palate identifies risk variants near MAFB and ABCA4. Nat Genet 2010;42:525-9.

11 Mangold E, Ludwig KU, Birnbaum S, Baluardo C, Ferrian M, Herms S, Reutter H, de Assis NA, Chawa TA, Mattheisen M, Steffens M, Barth S, Kluck N, Paul A, Becker J, Lauster C, Schmidt G, Braumann B, Scheer M, Reich RH, Hemprich A, Pötzsch S, Blaumeiser B, Moebus S, Krawczak M, Schreiber S, Meitinger T, Wichmann HE, Steegers-Theunissen RP, Kramer FJ, Cichon S, Propping P, Wienker TF, Knapp M, Rubini M, Mossey PA, Hoffmann P, Nöthen MM. Genome-wide association study identifies two susceptibility loci for nonsyndromic cleft lip with or without cleft palate. Nat Genet 2010;42:24-6.

12 Sun $Y$, Huang $Y$, Yin A, Pan Y, Wang Y, Wang C, Du Y, Wang M, Lan F, Hu Z, Wang G,

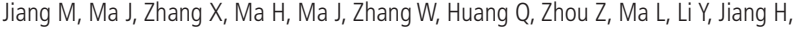
Xie L, Jiang Y, Shi B, Cheng J, Shen H, Wang L, Yang Y. Genome-wide association study identifies a new susceptibility locus for cleft lip with or without a cleft palate. Nat Commun 2015;6:6414.

13 Wolf ZT, Brand HA, Shaffer JR, Leslie EJ, Arzi B, Willet CE, Cox TC, McHenry T, Narayan N, Feingold E, Wang X, Sliskovic S, Karmi N, Safra N, Sanchez C, Deleyiannis FW, Murray JC, Wade CM, Marazita ML, Bannasch DL. Genome-wide association studies in dogs and humans identify ADAMTS20 as a risk variant for cleft lip and palate. PLOS Genet 2015;11:e1005059.

14 Leslie EJ, Carlson JC, Shaffer JR, Feingold E, Wehby G, Laurie CA, Jain D, Laurie CC, Doheny KF, McHenry T, Resick J, Sanchez C, Jacobs J, Emanuele B, Vieira AR, Neiswanger K, Lidral AC, Valencia-Ramirez LC, Lopez-Palacio AM, Valencia DR, Arcos-Burgos M, Czeizel AE, Field LL, Padilla CD, Cutiongco-de la Paz EM, Deleyiannis F, Christensen K, Munger RG, Lie RT, Wilcox A, Romitti PA, Castilla EE, Mereb JC, Poletta FA, Orioli IM, Carvalho FM, Hecht JT, Blanton SH, Buxó CJ, Butali A, Mossey PA, Adeyemo WL, James O, Braimah RO, Aregbesola BS, Eshete MA, Abate F, Koruyucu M, Seymen F, Ma L, de Salamanca JE, Weinberg SM, Moreno L, Murray JC, Marazita ML. A multi-ethnic genome-wide association study identifies novel loci for non-syndromic cleft lip with or without cleft palate on 2p24.2, 17q23 and 19q13. Hum Mol Genet 2016;25:ddw104-72.

15 Ludwig KU, Mangold E, Herms S, Nowak S, Reutter H, Paul A, Becker J, Herberz R, AlChawa T, Nasser E, Böhmer AC, Mattheisen M, Alblas MA, Barth S, Kluck N, Lauster C, Braumann B, Reich RH, Hemprich A, Pötzsch S, Blaumeiser B, Daratsianos N, Kreusch T, Murray JC, Marazita ML, Ruczinski I, Scott AF, Beaty TH, Kramer FJ, Wienker TF, Steegers-Theunissen RP, Rubini M, Mossey PA, Hoffmann P, Lange C, Cichon S, Propping P, Knapp M, Nöthen MM. Genome-wide meta-analyses of nonsyndromic cleft lip with or without cleft palate identify six new risk loci. Nat Genet 2012:44:968-71.

16 Leslie EJ, Carlson JC, Shaffer JR, Butali A, Buxó CJ, Castilla EE, Christensen K, Deleyiannis FW, Leigh Field L, Hecht JT, Moreno L, Orioli IM, Padilla C, Vieira AR, Wehby GL, Feingold E, Weinberg SM, Murray JC, Beaty TH, Marazita ML. Genomewide meta-analyses of nonsyndromic orofacial clefts identify novel associations between FOXE1 and all orofacial clefts, and TP63 and cleft lip with or without cleft palate. Hum Genet 2017;136:275-86.

17 Yu Y, Zuo X, He M, Gao J, Fu Y, Qin C, Meng L, Wang W, Song Y, Cheng Y, Zhou F, Chen G, Zheng X, Wang X, Liang B, Zhu Z, Fu X, Sheng Y, Hao J, Liu Z, Yan H, Mangold E, Ruczinski I, Liu J, Marazita ML, Ludwig KU, Beaty TH, Zhang X, Sun L, Bian Z. Genomewide analyses of non-syndromic cleft lip with palate identify 14 novel loci and genetic heterogeneity. Nat Commun 2017;8:14364.

18 Beaty TH, Marazita ML, Leslie EJ. Genetic factors influencing risk to orofacial clefts: today's challenges and tomorrow's opportunities. F1000Res 2016;5:2800.

19 Manolio TA, Collins FS, Cox NJ, Goldstein DB, Hindorff LA, Hunter DJ, McCarthy MI, Ramos EM, Cardon LR, Chakravarti A, Cho JH, Guttmacher AE, Kong A, Kruglyak L, Mardis E, Rotimi CN, Slatkin M, Valle D, Whittemore AS, Boehnke M, Clark AG, Eichler EE, Gibson G, Haines JL, Mackay TF, McCarroll SA, Visscher PM. Finding the missing heritability of complex diseases. Nature 2009;461:747-53.

20 Desmyter L, Ghassibe M, Revencu N, Boute O, Lees M, François G, Verellen-Dumoulin C, Sznajer Y, Moncla A, Benateau H, Claes K, Devriendt K, Mathieu M, Van Maldergem L, Addor MC, Drouin-Garraud V, Mortier G, Bouma M, Dieux-Coeslier A, Genevieve D, Goldenberg A, Gozu A, Makrythanasis P, McEntagart U, Sanchez A, Vilain C, Vermeer $S$, Connell F, Verheij J, Manouvrier S, Pierquin G, Odent S, Holder-Espinasse M, VincentDelorme C, Gillerot Y, Vanwijck R, Bayet B, Vikkula M. IRF6 screening of syndromic and a priori non-syndromic cleft lip and palate patients: identification of a new type of minor VWS sign. Mol Syndromol 2010;1:67-74.

21 Jugessur A, Shi M, Gjessing HK, Lie RT, Wilcox AJ, Weinberg CR, Christensen K, Boyles AL, Daack-Hirsch S, Trung TN, Bille C, Lidral AC, Murray JC. Genetic determinants of facial clefting: analysis of 357 candidate genes using two national cleft studies from Scandinavia. PLoS One 2009:4:e5385.

22 Peyrard-Janvid M, Leslie EJ, Kousa YA, Smith TL, Dunnwald M, Magnusson M, Lentz BA, Unneberg P, Fransson I, Koillinen HK, Rautio J, Pegelow M, Karsten A, BaselVanagaite L, Gordon W, Andersen B, Svensson T, Murray JC, Cornell RA, Kere J, Schutte BC. Dominant mutations in GRHL3 cause Van der Woude Syndrome and disrupt oral periderm development. Am J Hum Genet 2014;94:23-32.

23 Lemay P, De Marco P, Emond A, Spiegelman D, Dionne-Laporte A, Laurent S, Merello E, Accogli A, Rouleau GA, Capra V, Kibar Z. Rare deleterious variants in GRHL3 are associated with human spina bifida. Hum Mutat 2017;38:716-24.

24 Eshete MA, Liu H, Li M, Adeyemo WL, Gowans LJJ, Mossey PA, Busch T, Deressa W, Donkor P, Olaitan PB, Aregbesola BS, Braimah RO, Oseni GO, Oginni F, Audu R, Onwuamah C, James O, Augustine-Akpan E, Rahman LA, Ogunlewe MO, Arthur FKN, Bello SA, Agbenorku P, Twumasi P, Abate F, Hailu T, Demissie Y, Hailu A, Plange-Rhule G, Obiri-Yeboah S, Dunnwald MM, Gravem PE, Marazita ML, Adeyemo AA, Murray JC, Cornell RA, Butali A. Loss-of-function GRHL3 variants detected in African patients with isolated cleft palate. J Dent Res 2018:97:22034517729819.

25 Celli J, Duijf P, Hamel BC, Bamshad M, Kramer B, Smits AP, Newbury-Ecob R, Hennekam RC, Van Buggenhout G, van Haeringen A, Woods CG, van Essen AJ, de Waal R, Vriend G, Haber DA, Yang A, McKeon F, Brunner HG, van Bokhoven H. Heterozygous germline mutations in the p53 homolog p63 are the cause of EEC syndrome. Cell 1999;99:143-53.

26 Aradhya S, Lewis R, Bonaga T, Nwokekeh N, Stafford A, Boggs B, Hruska K, Smaoui $\mathrm{N}$, Compton JG, Richard G, Suchy S. Exon-level array CGH in a large clinical cohort demonstrates increased sensitivity of diagnostic testing for Mendelian disorders. Genet Med 2012;14:594-603.

27 Vanbokhoven H, Melino G, Candi E. Declercq W. p63, a story of mice and men. J Invest Dermatol 2011;131:1196-207.

28 Jewell R, Eng B, Coates A, Hewitt S, Hobson E. 3q27.3 Microdeletion syndrome: further delineation of the second region of overlap and atopic dermatitis as a phenotypic feature. Clin Dysmorphol 2017;26:154-6.

29 Ponzi E, Asaro A, Orteschi D, Genuardi M, Zollino M, Gurrieri F. Variable expressivity of a familial $1.9 \mathrm{Mb}$ microdeletion in $3 \mathrm{q} 28$ leading to haploinsufficiency of TP63: refinement of the critical region for a new microdeletion phenotype. Eur J Med Genet 2015;58:400-5.

30 Fulcoli FG, Franzese M, Liu X, Zhang Z, Angelini C, Baldini A. Rebalancing gene haploinsufficiency in vivo by targeting chromatin. Nat Commun 2016;7:11688.

31 Chen L, Fulcoli FG, Ferrentino R, Martucciello S, Illingworth EA, Baldini A. Transcriptional control in cardiac progenitors: Tbx 1 interacts with the BAF chromatin remodeling complex and regulates Wnt5a. PLoS Genet 2012;8:e1002571.

32 Goodship J, Cross I, Scambler P, Burn J. Monozygotic twins with chromosome 22q11 deletion and discordant phenotype. J Med Genet 1995;32:746-8.

33 Pan Y, Wang ZG, Liu XY, Zhao H, Zhou N, Zheng GF, Qiu XB, Li RG, Yuan F, Shi HY, Hou $X M$, Yang YQ. A Novel TBX1 Loss-of-function mutation associated with congenital heart disease. Pediatr Cardiol 2015;36:1400-10.

34 Wang ZM, Luo JQ, Xu LY, Zhou HH, Zhang W. Harnessing low-density lipoprotein receptor protein 6 (LRP6) genetic variation and Wnt signaling for innovative diagnostics in complex diseases. Pharmacogenomics J 2017.

35 Tamai K, Semenov M, Kato Y, Spokony R, Liu C, Katsuyama Y, Hess F, SaintJeannet JP, He X. LDL-receptor-related proteins in Wnt signal transduction. Nature 2000;407:530-5

36 Lei Y, Fathe K, McCartney D, Zhu H, Yang W, Ross ME, Shaw GM, Finnell RH. Rare LRP6 variants identified in spina bifida patients. Hum Mutat 2015;36:342-9.

37 Allache R, Lachance S, Guyot MC, De Marco P, Merello E, Justice MJ, Capra V, Kibar Z. Novel mutations in Lrp6 orthologs in mouse and human neural tube defects affect a highly dosage-sensitive Wnt non-canonical planar cell polarity pathway. Hum Mol Genet 2014;23:1687-99.

38 Massink MP, Créton MA, Spanevello F, Fennis WM, Cune MS, Savelberg SM, Nijman IJ, Maurice MM, van den Boogaard MJ, van Haaften G. Loss-of-function mutations in the WNT co-receptor LRP6 cause autosomal-dominant oligodontia. Am J Hum Genet 2015;97:621-6.

39 Ockeloen CW, Khandelwal KD, Dreesen K, Ludwig KU, Sullivan R, van Rooij I, Thonissen M, Swinnen S, Phan M, Conte F, Ishorst N, Gilissen C, RoaFuentes L, van de Vorst M, Henkes A, Steehouwer M, van Beusekom E, Bloemen M, Vankeirsbilck B, Bergé S, Hens G, Schoenaers J, Poorten VV, Roosenboom J, Verdonck A, Devriendt K, Roeleveldt N, Jhangiani SN, Vissers L, Lupski JR, de Ligt J, Von den Hoff JW, Pfundt R, Brunner HG, Zhou H, Dixon J, Mangold E, van Bokhoven H, Dixon MJ, Kleefstra T, Hoischen A, Carels CEL. Novel mutations in LRP6 highlight the role of WNT signaling in tooth agenesis. Genet Med 2016;18:1158-62.

40 Tamai K, Zeng X, Liu C, Zhang X, Harada Y, Chang Z, He X. A mechanism for Wnt coreceptor activation. Mol Cell 2004;13:149-56.

41 Mangold E, Böhmer AC, Ishorst N, Hoebel AK, Gültepe P, Schuenke H, Klamt J, Hofmann A, Gölz L, Raff R, Tessmann P, Nowak S, Reutter H, Hemprich A, Kreusch T, Kramer FJ, Braumann B, Reich R, Schmidt G, Jäger A, Reiter R, Brosch S, Stavusis J, Ishida M, Seselgyte R, Moore GE, Nöthen MM, Borck G, Aldhorae KA, Lace B, Stanier $P$, Knapp M, Ludwig KU. Sequencing the GRHL3 coding region reveals rare truncating mutations and a common susceptibility variant for nonsyndromic cleft palate. Am J Hum Genet 2016;98:755-62. 


\section{Developmental defects}

42 Leslie EJ, Koboldt DC, Kang CJ, Ma L, Hecht JT, Wehby GL, Christensen K, Czeizel AE, Deleyiannis FW, Fulton RS, Wilson RK, Beaty TH, Schutte BC, Murray JC, Marazita ML. IRF6 mutation screening in non-syndromic orofacial clefting: analysis of 1521 families. Clin Genet 2016;90:28-34.

43 Jezewski PA, Vieira AR, Nishimura C, Ludwig B, Johnson M, O'Brien SE, Daack-Hirsch S, Schultz RE, Weber A, Nepomucena B, Romitti PA, Christensen K, Orioli IM, Castilla EE, Machida J, Natsume N, Murray JC. Complete sequencing shows a role for MSX1 in non-syndromic cleft lip and palate. J Med Genet 2003;40:399-407.
44 Marçano AC, Doudney K, Braybrook C, Squires R, Patton MA, Lees MM, Richieri-Costa A, Lidral AC, Murray JC, Moore GE, Stanier P. TBX22 mutations are a frequent cause of cleft palate. J Med Genet 2004;41:68-74.

45 Limaye N, Boon LM, Vikkula M. From germline towards somatic mutations in the pathophysiology of vascular anomalies. Hum Mol Genet 2009;18:R65-R74.

46 Limaye N, Kangas J, Mendola A, Godfraind C, Schlögel MJ, Helaers R, Eklund L, Boon LM, Vikkula M. Somatic activating PIK3CA mutations cause venous malformation. Am J Hum Genet 2015;97:914-21. 